\title{
LETRAMENTO ACADÊMICO E DESENVOLVIMENTO DA ESCRITA POR ALUNOS INDÍGENAS EM UMA LICENCIATURA EM EDUCAÇÃO DO CAMPO, BRASIL
}

\section{ACADEMIC LITERACY, AND DEVELOPMENT OF WRITING BY INDIGENOUS STUDENTS IN A DEGREE IN RURAL EDUCATION, BRAZIL}

\author{
Milena dos Santos ${ }^{1}$ \\ Cícero da Silva ${ }^{2}$
}

\begin{abstract}
Resumo: Este artigo analisa dificuldades relacionadas à escrita por parte de alunos indígenas do curso de Licenciatura em Educação do Campo: Códigos e Linguagens - Artes e Música da Universidade Federal do Tocantins. O estudo ancora-se nas teorias do letramento, mais especificamente na perspectiva do letramento acadêmico. Trata-se de uma pesquisa de campo, de abordagem qualitativo-interpretativista. Os resultados da pesquisa apontaram que uma das principais dificuldades encontradas pelos alunos indígenas no espaço acadêmico é o uso da língua portuguesa, sugerindo a necessidade do desenvolvimento de ações capazes de ajudar os estudantes na produção de gêneros escritos, contribuindo assim para a permanência deles na universidade.
\end{abstract}

Palavras-chave: escrita; letramento acadêmico; indígenas; Educação do Campo

Abstract. This paper analyzes difficulties related to writing by indigenous students in the Degree in Rural Education: Codes and Languages - Arts and Music at the Federal University of Tocantins. The study is based on literacy theories, more specifically from the perspective of academic literacy. It is a field research, with a qualitative-interpretative approach. The results of the research pointed out that one of the main difficulties encountered by indigenous students in the academic space is the use of the Portuguese language, suggesting the need to develop actions capable of helping students in the production of written genres, thus contributing to their permanence in the university.

Keywords: writing; academic literacy; indigenous; Rural Education

\section{Introdução}

Este artigo integra uma pesquisa desenvolvida no curso de Licenciatura em Educação do Campo: Códigos e Linguagens - Artes e Música da Universidade Federal do Tocantins (UFT), Câmpus de Tocantinópolis. O objetivo do estudo é analisar dificuldades relacionadas à escrita de

\footnotetext{
${ }^{1}$ Mestranda do Programa de Pós-Graduação em Letras: Ensino de Língua e Literatura (PPGL) da Universidade Federal do Tocantins (UFT) e Bolsista da Coordenação de Aperfeiçoamento de Pessoal de Nível Superior (CAPES). Araguaína, Brasil. E-mail: milenasantos11@ @otmail.com Orcid: https://orcid.org/0000-0001-5652-0388

${ }^{2}$ Doutor e mestre em Letras: Ensino de Língua e Literatura pela Universidade Federal do Tocantins (UFT). Professor Adjunto da UFT, atuando no curso de Licenciatura em Educação do Campo: Códigos e Linguagens - Artes e Música - Câmpus de Tocantinópolis e no Programa de Pós-Graduação em Letras: Ensino de Língua e Literatura - Câmpus de Araguaína, Brasil. E-mail: cicolinas@yahoo.com.br Orcid: https://orcid.org/0000-0001-6071-6711
} 
gêneros acadêmicos por parte de alunos indígenas da referida Licenciatura (SANTOS, 2018). Ademais, embora os povos indígenas brasileiros vivam em uma realidade sociocultural muito diferente daquela que é imposta pela academia, principalmente quanto à produção acadêmicocientífica e ao uso do português (herança do colonizador europeu e língua oficial) na escrita e na oralidade, com exceção das escolas indígenas, esta é a língua que precisam utilizar no sistema formal de ensino nas escolas da educação básica e no ensino superior. Ou seja, o português é uma língua adicional para os indígenas brasileiros, e não a materna. Portanto, usar a língua portuguesa com eficiência representa para os indígenas um grande desafio diário (BRITO; LIMA, 2018) ao longo da graduação.

É importante destacarmos que, por um lado, os indígenas da etnia Apinajeje ${ }^{3}$ colaboradores da pesquisa possuem a língua materna Apinajé e aprendem a falar a língua portuguesa somente quando estão nos primeiros anos do Ensino Fundamental. Por outro lado, na esfera escolar eles não escrevem gêneros acadêmicos, como artigo, fichamento, resenhas, resumos acadêmicos, sínteses, entre outros. Apesar disso, quando ingressam na universidade os indígenas (e demais egressos da educação básica brasileira) são obrigados a se adequarem à nova realidade: precisam produzir diferentes gêneros acadêmicos. E é neste momento que devemos nos lembrar dos significados de letramento do professor (KLEIMAN, 2009) e do letramento acadêmico (LEA; STREET, 2014), pois o professor deve adotar metodologias apropriadas à realidade da turma e levar em consideração o meio sociocultural em que os estudantes vivem e, a partir disto, mostrar e oferecer ferramentas capazes de ajudá-los a superar as barreiras linguístico-discursivas.

Estudos sobre a escrita no ensino superior no Brasil, especialmente os que enfocam o chamado letramento acadêmico, ganham espaço nas pesquisas do país sobretudo nas duas últimas décadas. Muitos trabalhos focalizam o letramento acadêmico de alunos de graduação não indígenas (MARINHO, 2010; FIAD; SILVA, 2014), mas nossa pesquisa procurou compreender as práticas de escrita envolvendo a produção de um gênero escrito específico por estudantes indígenas do curso de Licenciatura em Educação do Campo focalizado. Os indígenas colaboradores da pesquisa fazem

\footnotetext{
${ }^{3}$ Adotamos a grafia "Apinajé" ao longo deste artigo em virtude de seu uso, embora também seja recorrente o emprego de "Apinayé" na literatura. Vale ressaltar que, em seus Registros Gerais (RG), alguns indígenas dessa etnia trazem o sobrenome "Apinagé" ou "Apinajé". Ademais, segundo Nimuendajú (1956), o nome da comunidade foi citado, pela primeira vez, na forma de "pinarés" e "pinagés", passando, posteriormente, para "Apinayé".
} 
parte da etnia Apinajé e seu território está localizado no extremo norte do estado do Tocantins, em uma microrregião conhecida como Bico do Papagaio.

Para tanto, analisamos no estudo as dificuldades relacionadas à escrita do gênero do discurso denominado Diário de processo criativo por alunos indígenas do curso de Licenciatura em Educação do Campo: Códigos e Linguagens - Artes e Música da UFT, Câmpus de Tocantinópolis. A produção do referido gênero ocorreu na disciplina Seminário Integrador II em 2016-2 e foi desenvolvida pelos estudantes levando-se em consideração as práticas em sala de aula e em suas comunidades. Para analisar os textos que integram os exemplares do Diário de processo criativo, estabelecemos as seguintes categorias de análise: (1) marcas de reescrita; (2) análise/intervenções do professor/orientador; e (3) aspectos linguísticos. Os dados também incluem entrevistas semiestruturadas realizadas com os oito estudantes indígenas colaboradores da investigação. Esta pesquisa utilizou do método pesquisa de campo, de abordagem qualitativointerpretativista.

O trabalho tem sua relevância uma vez que são raras as pesquisas que focalizam o letramento acadêmico envolvendo estudantes indígenas no Brasil. Pensar o impacto da dificuldade com o letramento acadêmico sofrido pelos alunos indígenas é uma tarefa urgente não só para os pesquisadores que se dedicam às questões indígenas mas também para muitos professores que atuam nas universidades. Por isso, também procuramos compreender no estudo qual o ponto de vista dos alunos indígenas acerca da produção textual, especialmente a escrita na universidade e identificar as principais dificuldades enfrentadas por eles no momento da escrita de gêneros acadêmicos.

Portanto, este trabalho está estruturado em duas partes principais. Na primeira, apresentamos a introdução e a perspectiva teórica assumida na pesquisa. Na segunda parte, apresentamos os procedimentos metodológicos da pesquisa, assim como as análises e discussão dos dados. À guisa de conclusão, ao final o trabalho traz uma síntese dos principais resultados obtidos na pesquisa.

\section{Os estudos do Letramento}

Quando falamos acerca de letramento é fundamental compreendermos a complexidade desse termo. Inicialmente o letramento estava associado à alfabetização e ao ato de ler e escrever, 
mas esta associação acabou sofrendo grandes críticas, pois muitos pesquisadores acreditavam que o letramento vai além do ato de ler e escrever, o qual deve ser pensado como um fenômeno social (KLEIMAN, 1995; STREET, 2014). Em seu estudo, Kleiman (1995) defende que o letramento não se reduz à escrita, mas que este engloba conhecimento e vivência conexos a alguns gêneros discursivos e seus usos sociais. Assim, a partir das pesquisas originárias no New London Group, alicerçadas pelos Novos Estudos do Letramento (NEL), letramento passou a ser compreendido como um fenômeno social que está ligado às práticas sociais de usos da leitura e escrita presentes em determina comunidade.

No Brasil, identificamos duas definições de letramento que merecem nossa atenção, sendo estas apresentadas por Soares (2019) e Kleiman (1995). Soares (2019, p. 39) traz um enfoque mais individual e estabelece letramento como "estado ou condição que adquire um grupo social ou um indivíduo como consequência de ter-se apropriado da escrita de suas práticas sociais”. Esta concepção proporciona aos sujeitos um estado ou condição de aceitação no mundo letrado, além de presumir "saberes, atitudes e comportamentos de uma pessoa (ou de um grupo) que, por ter-se apropriado da escrita, consegue oferecer determinadas respostas a certas demandas" (TINOCO, 2008, p. 106). Ademais, tal concepção se ajusta ao conceito de letramento escolar, assemelhando a "algo que pode ser mensurado por parâmetros predefinidos para cada série, nível ou grau de escolaridade" (TINOCO, 2008, p. 106).

Por sua vez, Kleiman (1995, p. 11) associa letramento a um “[...] conjunto de práticas sociais, cujos modos específicos de funcionamento têm implicações importantes para as formas pelas quais os sujeitos envolvidos nessas práticas constroem relações de identidade e de poder". Nesta perspectiva, letramento leva em consideração as práticas sociais de leitura e escrita e os eventos em que estes estão situados, ou seja, o letramento ultrapassa as barreiras da aquisição da escrita e de seu código. Nesta perspectiva, devemos considerar que o letramento "[...] nos acompanha não só na escola, mas a vida inteira e nas mais diferentes esferas de atividade e com propósitos variados, possibilitando nossa inserção e participação em eventos de diferentes níveis sociais e/ou de escolaridade" (SILVA, 2019, p. 479).

Portanto, o letramento está ligado diretamente às práticas sociais de usos da leitura e da escrita e de suas tecnologias, embora muitos sujeitos que participam de tais práticas não sejam considerados alfabetizados eles fazem parte da sociedade letrada. Afinal, o cotidiano destes sujeitos 
também é povoado de elementos da cultura letrada aos quais são submetidos frequentemente nas interações. Rojo (2009, p. 98) nos explica ainda que o termo letramento

[...] busca recobrir os usos e práticas sociais de linguagem que envolvem a escrita de uma ou de outra maneira, sejam eles valorizados, locais ou globais, recobrindo contextos sociais diversos (família, igreja, trabalho, mídias, escola etc.), numa perspectiva sociológica, antropológica e sociocultural.

Com base no excerto, depreendemos que o termo letramento possui uma gama de sentidos e perpassa por diversas áreas do conhecimento, indo além da leitura e da escrita, um fenômeno social que não pode ser compreendido no singular, mas sim no plural, "letramentos". Portanto, neste estudo estamos compreendendo letramento como

[...] um fenômeno plural, dado o reconhecimento de que não existe apenas um tipo de letramento, mas letramentos, que surgem conforme o avanço tecnológico e o desenvolvimento da sociedade. Atrelado a isso, está o reconhecimento de diversas agências letradas - acadêmica, escolar, midiática, digital, entre outras -, que se constituem a partir de eventos e práticas que as definem como tal. Em outras palavras, conceber o letramento como um fenômeno plural sinaliza a compreensão de que a língua não é única, homogênea, universal e atemporal, mas ligada à complexidade da vida moderna. Além disso, a pluralidade se configura na interrelação social e individual, ou seja, os usos da escrita podem ser entendidos a partir da correlação entre o contexto sociocultural do qual o agente faz parte e a sua história de vida. (SILVA; ARAÚJO, 2012, p. 697)

Entendemos que conceituar o letramento no singular é negar que existe uma gama de letramentoS presente nas diversas formas da vida, nos diversos espaços e ambientes, é negar que letramento está integrado com a cultura e com o perfil socioeconômico dos sujeitos. Em outros termos, como defende Oliveira (2010, p. 329), “enxergar o letramento como algo 'singular' é esquecer que a vida social é permeada por linguagem de múltiplas formas e destinada a diferentes usos" e é por compreendermos letramento no plural que “[...] vale a pena problematizar, examinando as diversas facetas que o constituem".

Tendo em vista a concepção de letramento apresentado, consideramos que o sujeito ao adentrar o espaço da academia se deparara com novas práticas de letramento, ou seja, se depara com o letramento acadêmico (MARINHO, 2010). No espaço da universidade os discentes se deparam com gêneros do discurso escritos específicos desta esfera social. Logo, todo o conhecimento de escrita advindo da formação na educação básica e todo o letramento já adquirido pelos alunos irão colidir com as práticas de letramento acadêmico. 
O conceito de letramento acadêmico surge com os Novos Estudos do Letramento. Segundo Lêdo (2013, p. 57), “[...] o letramento acadêmico significa mais do que leitura e escrita por si, pois implica (re)conhecer estratégias textuais, linguísticas e discursivas inseridas em determinado campo do conhecimento, bem como as relações sociais que permeiam essas práticas". Quando ingressam na universidade, os alunos entram com seus conhecimentos e letramentos adquiridos ao longo de sua vida, ou seja, entram com os letramentos escolares e informais. No espaço acadêmico, eles aprendem um novo tipo de letramento, que é específico do domínio acadêmico. Nesse sentido, letramento acadêmico pode ser compreendido como "[...] o processo de desenvolvimento de habilidades e conhecimentos sobre as formas de interagir com a escrita para os fins específicos desse domínio [acadêmico], sem, contudo, desconsiderar, nessas interações com a escrita, a história de letramento dos alunos" (OLIVEIRA, 2010, p. 5).

O modelo de letramento acadêmico, segundo as análises de Araújo e Bezerra (2013, p. 15), não se atem a meras ações técnicas "de leitura e produção textual, ou à produção de gêneros discursivos acadêmicos com fins avaliativos, mas concebe o letramento como prática social numa relação intrínseca entre indivíduos, habilidades e realidade". O letramento que caracteriza o ambiente acadêmico alude os acadêmicos/discentes para uma direção que seja natural às maneiras privadas de pensar, ser, fazer, ler e escrever, muitas destas sendo típicas desse contexto social, o meio acadêmico (FISCHER, 2008).

Street (2014) ainda caracteriza letramento a partir de dois modelos: autônomo e ideológico. Este primeiro modelo, o autônomo, prevalece na sociedade e se reproduz, sem poucas mudanças, desde o século passado XX. Esse modelo destaca que a escrita se completa por si só, sem sujeitarse a outros elementos para sua compreensão, e nem precisaria de saber o contexto que a mesma foi escrita para seu entendimento. Portanto, o processo de interpretação careceria somente do funcionamento lógico interno ao texto escrito, sem depender das reformulações estratégicas que é característica da oralidade (KLEIMAN, 1995).

Já o segundo modelo, o modelo ideológico, compreende o letramento como “prática social”, e não somente uma obra técnica e neutra, onde o contexto deve ser decisivo da maneira que as pessoas irão lidar com a escrita. Nessa perspectiva, o letramento vincula-se ao contexto social onde os indivíduos estejam arraigados (EUZÉBIO; CERUTTI-RIZZATTI, 2013). Por isso, propõe-se uma "visão culturalmente" antes afetuosa das práticas de letramento, uma vez que estas se alternam 
de cada meio social para outro. O modelo ideológico não implica uma afinidade causal entre letramento e "progresso", "civilização", ou "modernidade"; ele implica a essência e pesquisa dos atributos de grandes áreas de interconexão entre "práticas orais e práticas letradas", já que este não busca a grande divisão entre a oralidade e a escrita.

Além de ser caracterizado por estes dois modelos, autônomo e ideológico, o letramento abrange outros elementos, como as práticas e eventos de letramentos. Tanto as práticas quanto os eventos de letramento fazem parte do cotidiano dos sujeitos, grupos sociais, e ambos estão estreitamente entrelaçados. A partir das práticas de letramento conseguimos ampliar e detalhar a análise e a interpretação das práticas sociais que transpassam a linguagem escrita e as concepções de escrita e leitura dominantes de determinado grupo social. Silva (2007, p. 40) nos explica que

O conceito de práticas de letramento se refere ao modo como são construídos os significados de letramento nos contextos sociais e culturais em que a leitura e a escrita desempenham um papel. Tem a ver com a experiência de leitura e escrita que as pessoas adquirem nas práticas sociais.

Cada sujeito, cada grupo social possui suas próprias práticas de letramento e estas vão sendo moldadas a partir da mudança que ocorre nos grupos sociais ou mesmo em cada sujeito, sendo possível identificar as práticas de letramento a partir de um domínio social. As práticas de letramento são perceptíveis por meio dos eventos de letramento. Já os eventos de letramento são mais específicos e transcorrem de práticas de letramento e ambos se localizam em estruturas sociais. Para que se possa entender as práticas de letramento é necessário considerar o tempo e o espaço que estas estão inseridas, ou seja, é necessário levar em consideração onde e quando os eventos de letramento aconteceram, uma vez que estes ocorrem em um contexto cultural e se constituem de práticas já existentes.

Kleiman (1995, p. 40) afirma que os eventos de letramento são "situações em que a escrita constitui parte essencial para fazer sentido da situação, tanto em relação à interação entre os participantes como em relação aos processos e estratégias interpretativa”. Logo, é necessário que se tenha um diálogo entre os participantes nos eventos de letramento, mesmo que ambos estejam distantes, ou seja, invisíveis. Uma das características dos eventos de letramento é sua maneira "generalizadora ou extensiva".

Portanto, "eventos são atividades em que o letramento tem uma função, são ocasiões em que o texto escrito faz parte da natureza das interações dos participantes e de seus processos 
interpretativos" (FISCHER, 2008, p. 178). É por intermédio dos eventos de letramento que podemos fazer a observação e análise da linguagem social. As práticas e eventos de letramento estão em todo o nosso cotidiano onde se há o uso da leitura, escrita e também se fazendo presente a oralidade, sendo que eventos e práticas de letramento se completam, em suas funções no dia a dia e para que possamos entender o que se passa nos meios sociais que se tem a leitura e escrita como práticas dominantes.

\section{Procedimentos metodológicos}

A partir da compreensão de que os indígenas Apinajé vivem imersos em uma realidade completamente diferente da realidade que é imposta pela academia, principalmente quanto à produção acadêmico-científica, e que tais sujeitos sociais possuem uma língua materna própria em suas comunidades, aprendem a falar a língua portuguesa apenas quando iniciam os seus primeiros anos do Ensino Fundamental, é que surgiu a necessidade de desenvolvermos este trabalho. Tratase de uma pesquisa de campo, de abordagem qualitativo-interpretativista.

A pesquisa de campo consiste em como o pesquisador observa os fatos e acontecimentos, gera os dados alusivos aos mesmos, analisa e interpreta-os tendo por base uma fundamentação teórica apropriada, objetivando assim compreender e explicar o problema pesquisado. Fonseca (2012, p. 23) enfatiza que o objetivo da pesquisa de campo é "conseguir informações e/ou conhecimentos acerca de um problema, para o qual se procura uma resposta, ou de uma hipótese, que se queira comprovar, ou ainda, descobrir novos fenômenos ou as relações entre eles".

O estudo também está pautado nos métodos da pesquisa qualitativa, pois ela admite obter opiniões pessoais dos participantes e estas podem ser conseguidas no seu espaço de vivência próprio. Santos e Santos (2010) reforçam que para a pesquisa qualitativa um elemento pode ser mais bem analisado/compreendido quando pesquisado no contexto em que este faz parte. "Para apreciá-lo de forma integrada, o pesquisador deve mergulhar na realidade, procurando interpretála a partir da perspectiva das pessoas nela envolvidas" (SANTOS; SANTOS, 2010, p. 44). Com isso, depreendemos que a pesquisa qualitativa tem um caráter mais aberto e flexível tanto para quem está sendo pesquisado quanto para o pesquisador.

Os colaboradores da pesquisa são oito alunos indígenas da etnia Apinajé vinculados ao curso de Licenciatura em Educação do Campo: Códigos e Linguagens - Artes e Música da UFT, 
Câmpus de Tocantinópolis, sendo sete homens e uma mulher. Eles vivem nas aldeias localizadas no território dessa etnia, situado nos municípios de Tocantinópolis, Maurilândia, São Bento, Itaguatins, Cachoeirinha e Nazaré, microrregião do Bico do Papagaio, estado do Tocantins. Os alunos residem nas seguintes aldeias: dois na aldeia Cocal Grande, dois na aldeia Pintada, dois na aldeia Furna Negra, um na aldeia Patizal e um na aldeia Boi Morto. A aldeia mais remota é a Patizal, que fica a cerca 70 km da UFT, Câmpus de Tocantinópolis (SANTOS, 2018).

Nesta pesquisa utilizamos de questionários semiestruturados e entrevistas como ferramentas de geração de dados. Estas ferramentas permitiram que pudéssemos obter dados relevantes para serem analisados, uma vez que os questionários semiestruturados consistem em "perguntas fechadas, mas que apresentam uma série de possíveis respostas, abrangendo várias facetas do mesmo assunto" (SANCHEZ, 2012, p.14). As perguntas utilizadas nos questionários têm caráter aberto, deixando o entrevistado livre para expor e defender seus pontos de vista. Portanto, foram realizadas entrevistas com os oito estudantes indígenas colaboradores da investigação.

Além disso, para analisar as dificuldades relacionadas à escrita, também coletamos exemplares do gênero do discurso denominado Diário de processo criativo, produzidos pelos estudantes indígenas colaboradores da pesquisa. A produção do referido gênero ocorreu na disciplina Seminário Integrador II em 2016-2 e foi desenvolvida pelos alunos levando-se em consideração as práticas em sala de aula e em suas comunidades. Para analisar os textos que integram os exemplares do Diário de processo criativo, estabelecemos três categorias de análise: (1) marcas de reescrita; (2) análise/intervenções do professor/orientador; e (3) aspectos linguísticos.

\subsection{A Licenciatura em Educação do Campo da UFT, lócus da pesquisa}

Conforme delineado na seção anterior, os dados da pesquisa foram gerados no curso de Licenciatura em Educação do Campo: Códigos e Linguagens - Artes e Música da Universidade Federal do Tocantins (UFT), Câmpus de Tocantinópolis. Trata-se de um curso que faz parte das políticas públicas para a Educação do Campo, uma reivindicação antiga dos povos do campo brasileiros. Este curso visa a preparar os educandos de forma que possuam uma atuação profissional “que vá para além da docência, e dê conta da gestão dos processos educativos que acontecem na escola e em seu entorno" (MOLINA; SÁ, 2011, p. 36). É um tipo de licenciatura que visa à 
formação de docentes que estejam comprometidos com a história, a cultura e os valores/saberes do campo.

As Licenciaturas em Educação do Campo (LPEC) tiveram início no Brasil com uma experiência piloto constituída de quatro cursos (MOLINA, 2015). No ano de 2006, o Ministério da Educação (MEC) convidou algumas Instituições Federais de Ensino Superior (IFES) no intuito de implantar cursos de graduação em Licenciatura em Educação do Campo. As IFES contempladas para o desenvolvimento de quatro projetos-piloto do curso foram: Universidade de Brasília (UnB), Universidade Federal da Bahia (UFBA), Universidade Federal de Sergipe (UFS) e Universidade Federal de Minas Gerais (UFMG). É importante ressaltar que essas universidades já acumulavam experiências com a formação de professores do campo e estavam envolvidas em projetos de gestão em parceria com os movimentos sociais do campo.

Dando sequência às ações, assim que implantou as turmas do projeto-piloto em 2007, o MEC criou o Programa de Apoio à Formação Superior em Licenciatura em Educação do Campo (Procampo). Tendo em vista as experiências exitosas das universidades (UnB, UFBA, UFS, UFMG) envolvidas com o projeto-piloto e reivindicações por mais cursos por parte dos movimentos sociais do campo, o MEC lançou respectivamente em 2008 e 2009 os Editais $n^{\circ}$ 02/2008 e nº 09/2009, no intuito de que as IFES apresentassem projetos visando à criação de novos cursos de LPEC. Estes editais corroboram o objetivo do Procampo, que é sustentar e promover projetos de cursos de licenciatura em educação do campo que integrem ensino, pesquisa e extensão e promovam a valorização da educação do campo e o estudo de questões relevantes concernentes ao campo e suas populações. Em 2012, por meio do MEC o governo Federal deu sequência às ações de apoio à política de formação de professores das escolas do campo, conforme previsto no Decreto n. 7.352/2010 (BRASIL, 2010), e lançou o Edital nº 02/2012 (BRASIL, 2012). Através da chamada pública do Edital n ${ }^{\circ}$ 02/2012 foram selecionados mais de 40 projetos de cursos de LPEC nas diversas áreas do conhecimento de universidades públicas das diferentes regiões brasileiras, dentre eles, o curso da UFT focalizado nesta pesquisa. Portanto, o Procampo consagra uma política pública única de formação para professores do campo no Brasil, embora esteja sob ameaça no governo atual.

A UFT, levando em consideração questões pertinentes referentes à Educação do Campo e todo o histórico de desigualdade que os povos do campo vêm passando ao longo de todos os anos 
e considerando as demandas dos trabalhadores e trabalhadoras do campo manifestadas através de associações comunitárias do Bico do Papagaio, que abrange 25 municípios, no ano de 2012, participou do Edital SESU/SETEC/SECADI n ${ }^{\circ}$ 02/2012, lançado pelo MEC. Essa IES foi contemplada com dois cursos de Licenciatura em Educação do Campo, um vinculado ao Câmpus de Tocantinópolis e outro ao Câmpus de Arraias (ALMEIDA, 2016; SILVA et al., 2017).

O Câmpus de Tocantinópolis da UFT optou pela oferta do curso de Licenciatura em Educação do Campo: Códigos e Linguagens - Artes e Música. O referido Câmpus está situado na microrregião do Bico do Papagaio, Norte do estado do Tocantins, sendo esta cidade situada às margens do Rio Tocantins, na divisa do estado do Tocantins com o estado do Maranhão, distante $530 \mathrm{~km}$ da capital, Palmas. Assim, o curso atende toda a microrregião do Bico do Papagaio, que faz divisa com o Sudoeste do Maranhão e Sudeste do estado do Pará (SILVA et al., 2017).

Tendo o curso como principal público os povos do campo, busca-se a participação de todos os camponeses: agricultores familiares, ribeirinhos, extrativistas, pescadores artesanais, assentados e reassentados da reforma agrária, acampados, quilombolas, indígenas, dentre outros. O curso visa a valorizar e melhorar o ensino nas escolas do campo. Daí, a importância de os próprios sujeitos do campo vinculados a essa LPEC buscarem essa valorização, sendo que eles terão a compreensão do valor real do seu povo, do território, da cultura e da identidade de cada um.

O ingresso dos discentes no curso de Licenciatura em Educação do Campo: Códigos e Linguagens - Artes e Música da UFT, desde a primeira turma (2014/1), ocorre através de processo seletivo específico e as vagas são distribuídas por quatro sistemas diferentes (Sistema Universal; Sistema de Cotas para Etnia Indígena; Sistema de Cotas para Quilombola; e Sistema de aplicação da Lei 12.711/2012), devendo o aluno optar por apenas um. Vale destacar que boa parte dos alunos selecionados pelo curso são indígenas.

Considerando as recomendações do MEC, o projeto do curso contempla a realidade sociocultural dos povos do campo, dispondo de organização curricular por etapas ou módulos equivalentes a semestres regulares cumpridos em alternância pedagógica entre Tempo Universidade (TU) e Tempo Comunidade (TC) (SILVA et al., 2017). Leva-se em consideração a educação como intrínseca à realidade específica do seu aluno, o que de certa forma facilita o acesso e permanência dos professores-alunos no curso. A alternância pedagógica, dentre outras coisas, 
permite que os alunos que vivem no/do campo não necessitem continuar no dilema de escolher entre a educação e sua vida no campo.

O TU constitui em atividades na universidade, que compreendem a parte constituinte das diferentes disciplinas do curso e do Seminário Integrador. As atividades do TC são realizadas no espaço de vivência dos alunos, a família, a comunidade, o meio socioprofissional, cuja finalidade e levá-los a refletir sobre os problemas, textos e demais questões discutidas no TU, além de realizarem pesquisas. Os alunos têm a oportunidade socializar com a comunidade em que convivem e demais colegas tudo o que foi debatido em sala de aula e levantar hipóteses acerca de possíveis soluções para os problemas (UFT, 2016).

A disciplina Seminário Integrador possui uma carga horária de 30 horas, divididas em 15 horas de TU e 15 horas de TC. Percebe-se que a alternância pedagógica reforçada por meio dessa disciplina que ela é desenvolvida em encontros no decorrer do TU e do TC, dois tempos e espaços formativos que permitem ao discente fazer reflexões entorno, sobretudo, das experiências vivenciadas no TC a partir do diálogo com outros autores sociais e a pesquisa. Assim, a divisão das horas da disciplina permite desenvolver as atividades reforçando a conexão entre os dois tempos de formação (TU-TC) (SILVA et al., 2017). O Seminário Integrador tem a finalidade de promover a integração semestral entre as demais disciplinas de um período a partir de um tema gerador, o que acaba deixando de lado o modelo tradicional posto nas licenciaturas tradicionais.

A geração dos dados da nossa pesquisa deu-se ao longo do desenvolvimento das atividades da disciplina Seminário Integrador II, em 2016-2, na turma que em 2018-2 estava no $6^{\circ}$ período da Licenciatura em Educação do Campo da UFT, Câmpus de Tocantinópolis. O trabalho proposto nesta disciplina constitui-se na produção de um audiovisual de um minuto, que tinha como tema gerador "Vida em imagem e som". Além deste audiovisual, os discentes deveriam elaborar o Diário de processo criativo, no qual consta o registro de todo o desenvolvimento da pesquisa, servindo assim como alicerce para visualização de todos os passos da obra audiovisual. O objetivo desse diário era "[...] acumular os registros relacionados ao percurso e às experiências vivenciadas durante a produção, compreendidas desde a concepção da ideia original à exibição pública do material audiovisual" (PAULA; BONILLA; SILVA, 2016, p. 177). Assim, os dados dos diários apresentados neste artigo também buscam compreender o processo de correção dos diários de 
processo criativo considerando os seguintes elementos: (1) marcas de reescrita; (2) análise/intervenções do professor/orientador; e (3) aspectos linguísticos.

\section{Análise e discussão dos dados}

\subsection{O gênero Diário de processo criativo}

Tomamos o Diário de processo criativo como gênero do discurso a partir da perspectiva bakhtiniana. Silva (2011, p. 60) pontua que “[...] os gêneros são responsáveis pela organização das situações de interação verbal da vida social". Assim, podemos dizer que os gêneros discursivos são motivados pelo domínio discursivo e fazem parte do ato de comunicar do ser humano. A efetivação textual dos gêneros é posta mediante a relação entre cognição, linguagem e práticas interacionais na averiguação dos dessemelhantes atos sociais mediados pela linguagem (PEREIRA; RODRIGUES, 2009).

O modo como foi escrito, por quem, qual o propósito e sequência tipológica que prevalece é que vai deixar claro o gênero a que cada texto pertence. Bakhtin (2006) observa que as demonstrações de um discurso definem-se mediante a natureza dos gêneros discursivos, característicos e compostos em situações demonstrativas típicas das esferas das relações sociais. Cada grupo social que se utiliza de uma língua desenvolve os seus próprios gêneros, ditando quais as formas genéricas e relativamente estáveis de amostra dos discursos.

Bakhtin (2006) argumenta que os gêneros do discurso trazem três elementos fundamentais: conteúdo temático, estilo linguístico e construção composicional, e estes são componentes alusivos das atividades de linguagem, os quais concebem as práticas sociais. Em linhas gerais, os gêneros atendem as necessidades de comunicação dos indivíduos quando estes utilizam a linguagem. Silva (2011, p. 63) afirma que "o uso da linguagem nas atividades da esfera acadêmica é primordial, sendo que constantemente seus atores recorrem à composição de enunciados (orais ou escritos) específicos para executar suas atividades ou expressar suas ideias".

O gênero discursivo é uma denominação que diz respeito a quaisquer aparecimentos concretos do discurso produzido pelos indivíduos em um grupo social do uso da linguagem (SILVA, 1999). A autora ainda enfatiza que os gêneros são maneiras de funcionamento da língua que todos os indivíduos constroem e atualizam por meio de texto, nas circunstâncias discursivas 
que nos rodeiam. São acontecimentos contextualmente estabelecidos, (re)aceitados por nós empiricamente.

Bakhtin (2006), considerando que os gêneros discursivos apresentam uma rica diversidade, arquitetou dois grupos para separá-los: gêneros discursivos primários e gêneros discursivos secundários. O Diário de processo criativo apresenta características do gênero discursivo secundário, uma vez que neste consta vivências dos acadêmicos, pois os temas surgiram a partir de suas realidades e se concretizou pela linguagem escrita.

Na sequência, a Tabela 1 apresenta os temas escolhidos pelos alunos indígenas da turma do $2^{\circ}$ período de 2016-2 para produção de audiovisuais de um minuto, o que comprova que eles escolheram temas recorrentes em suas vivências cotidianas:

Tabela 1. Temas da produção audiovisual dos alunos indígenas

\begin{tabular}{|l|c|}
\hline \multicolumn{1}{|c|}{ Tema } & Aluno \\
\hline 1. A pintura extraída a partir do fruto jenipapo & $\mathrm{C}$ \\
\hline $\begin{array}{l}\text { 2. Ritual em homenagem aos mortos na Aldeia São José (Corrida de } \\
\text { Tora), Tocantinópolis-TO }\end{array}$ & $\mathrm{I}$ \\
\hline 3. Ritual do corte de cabelo & $\mathrm{H} \mathrm{e} \mathrm{E}$ \\
\hline 4. Medicina da Aldeia São José, Tocantinópolis-TO & $\mathrm{D}$ \\
\hline 5. A importância das plantas medicinais & $\mathrm{F}$ \\
\hline 6. Processo de produção da farinha de mandioca na Aldeia Pintada & $\mathrm{G}$ \\
\hline 7. A importância do pé de babaçu para os Apinajé & $\mathrm{R}$ \\
\hline 8. O povo Apinajé e o movimento social e indígena & $\mathrm{A}$ \\
\hline
\end{tabular}

Fonte: Santos (2018, p. 59-60).

Todos os temas procuram resgatar a cultura do povo Apinajé. O Tema 1 trata de um fruto que é um marco na cultura Apinajé, o jenipapo, pois é com este fruto que são feitas todas as pinturas que contém um histórico de importância na história de vida/luta dos Apinajé. Já o Tema 2 trata de um ritual tradicional deste povo, que é realizado após um ano da morte da pessoa que está sendo homenageada. Desta maneira, tem toda uma cosmologia envolvida, da mesma maneira é o Tema 3. Os Temas 4 e 5 ressaltam a importância que as plantas têm para os indígenas Apinajé, sendo que tais plantas, muitas das vezes, substituem o remédio que é oferecido pelas unidades básicas de saúde. 
O Tema 6 aborda um modo de subsistência, a mandioca. Por sua vez, o Tema 7 discute a importância de uma das plantas que tem toda uma simbologia, uma vez que é de tal planta que se subtrai diversos elementos para a arrecadação de renda e subsistência. O Tema 8 focaliza as lutas e manifestações dos povos indígenas Apinajé. Estes temas surgiram de uma maneira com uma importância/relevância que se não fosse através da disciplina Seminário Integrador II, em outros termos, talvez não tivessem sido alcançados em uma atividade e adentrado o espaço da sala de aula na academia (SANTOS, 2018). Portanto, os exemplares do gênero Diário de processo criativo trazem os registros da experiência de cada um dos discentes acerca da produção do audiovisual a partir dos temas ilustrados na Tabela 1.

\subsection{A produção escrita do gênero e o trabalho docente}

O Diário de processo criativo é dividido em duas partes. A primeira é composta apenas da apresentação do diário e, a segunda, se subdivide em onze partes, sendo que em cada uma delas os acadêmicos devem expor sua opinião sem necessitar se embasar em algum autor. Neste diário, os acadêmicos puderam, no desenrolar do texto, registrar ideias, opiniões acerca da realidade que eles vivem. Como os temas escolhidos abarcam a realidade de todos, eles conseguiram expor seus sentimentos de uma forma geral e, sobretudo, conseguiram registrar fatos advindos do cotidiano.

A produção dos dois diários analisados neste artigo foi orientada por um professor da área da Linguagem, graduado em Letras - Licenciatura plena em Português-Inglês pela Universidade Estadual do Tocantins, especialista em Leitura e Produção Escrita, mestre e doutor em Letras: Ensino de Língua e Literatura pela Universidade Federal do Tocantins. Considerando que uma análise pode mostrar vários aspectos de um texto, preferimos levar em consideração ao analisar os textos de dois diários que integram o corpus da pesquisa as seguintes categorias: (1) marcas de reescrita; (2) análise/intervenções do professor/orientador; e (3) aspectos linguísticos.

A construção desse gênero possibilita uma aproximação das relações entre elementos/conhecimentos da instituição acadêmica e da realidade social dos produtores, neste caso, os discentes indígenas Apinajé. Mediante a construção do diário, os acadêmicos tiveram a oportunidade de conhecer novos aspectos da própria vida social e cultural, mobilizando assim conhecimento empírico e científico e impulsionando várias práticas sociais dos diferentes campos de conhecimentos que esses sujeitos fazem parte. Os dois diários foram produzidos pelos alunos 
identificados como C e G. ${ }^{4}$ Abaixo, ilustramos a seção "apresentação" do Diário de processo criativo do aluno G:

Este vídeo ira mostra todos os passos do processo de produção de farinha de mandioca, a farinha é muito boa, pois serve para nos alimentar, se nós não planta a mandioca não vamos ter farinha para o sustento da nossa família, junto com o plantio da mandioca também plantamos outros tipos de legumes como abobora, batata doce etc. A plantação nos da muito trabalho, as dificuldades são muitas, mas se não plantarmos não vamos ter o que comer. Este vídeo ira mostra um pouco da realidade de como nos fazemos a farinha para o nosso consumo. (Diário do aluno G)

Considerando que a apresentação/introdução de um gênero como o Diário de processo criativo deve conter o tema, justificativa, objetivo, ideia central e metodologia apresentados em parágrafos separados, na apresentação escrita pelo aluno G é perceptível apenas uma pequena exposição do que consta no vídeo produzido pelo discente e não o que deveria constar no diário. Nota-se também que o aluno escreveu as palavras utilizando a forma como elas são faladas, a variedade popular da língua, esquecendo-se de fazer algumas concordâncias, pôr acentos e pontos necessários para boa articulação das ideias no texto.

A seguir ilustramos uma imagem que traz as intervenções do professor/orientador no texto citado anteriormente:

Imagem 1. Intervenções no Diário do aluno G

${ }^{4}$ Por questões éticas, os nomes de todos os colaboradores desta pesquisa foram substituídos por pseudônimos. Advertimos o leitor que optamos por manter a grafia das palavras tal como elas aparecem nas entrevistas e nos Diários de processo criativo dos colaboradores. 


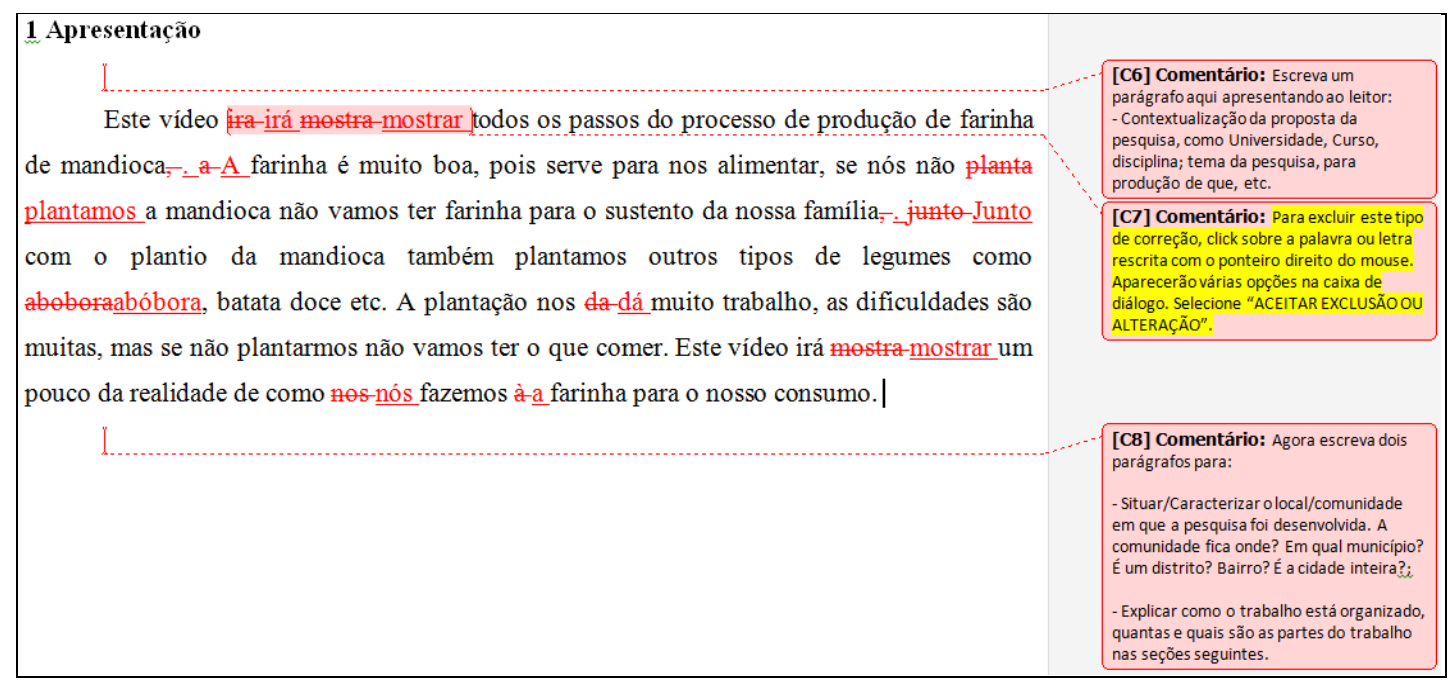

Fonte: Colaborador G, Diário 1 (2016, p. 4).

É necessário que o professor possa esclarecer da melhor maneira possível e com sugestões apropriadas, o que de concreto se pretende com a produção escrita de determinado gênero e de todas as etapas de tal gênero. Menegassi (2003, p. 55-56) pontua que a fase de reescrita é de suma importância e argumenta que a direção seja dada "ao aluno como um objetivo certo para a construção do texto", ressaltando ainda que "saber dosar e saber apresentar a finalidade da produção escrita é de competência do elaborador do comando, no caso, o professor”. Assim, de acordo com o autor, o professor tem a missão de orientar todo o procedimento de produção do texto, explanando claramente qual a finalidade do texto, a originalidade de cada gênero, deixando claro qual é o papel do professor no percurso do trabalho para que no final se tenha uma escrita eficaz.

Como o Diário de processo criativo produzido pelo Aluno $\mathrm{G}$ foi enviado por meio do correio eletrônico ao professor, sendo escrito no editor Microsoft Office Word, as correções/intervenções do professor vieram inseridas no corpo do próprio texto, como mostra o Imagem 1. Nas intervenções do professor, em alguns comentários o mesmo deixa claro o que deseja que seja reformulado no texto, já em outros, utiliza-se de perguntas para que o aluno possa refletir e reescrever o texto. Ao utiliza-se da interrogação, como no comentário "- Situar/caracterizar o local/comunidade em que a pesquisa foi desenvolvida. A comunidade fica onde? Em qual município? É um distrito? Bairro? É a cidade inteira?”, o docente cria um diálogo entre professor e aluno. No caso desta orientação, o professor ao utilizar-se da interrogação para suas intervenções 
o mesmo criou um diálogo direto com seu orientando, uma vez que de alguma forma pediu uma resposta. Na sequência, apresentamos a versão reescrita do texto ilustrado na Imagem 1, conforme intervenções do professor:

O vídeo que será apresentado no decorrer deste texto faz parte de uma proposta da disciplina Seminário Integrador II, do curso de Educação do Campo, da Universidade Federal do Tocantins, o qual estou cursando. O tema proposto para produção de um vídeo de um minuto denomina-se "Vida em imagem e som". Eu sou [...], sou casado, tenho três filhos e moro na aldeia Pintada, onde a produção de farinha é bastante importante para a subsistência dos que nela moram e por isso irei mostrar como se faz para que outras pessoas possam aprender. O vídeo irá mostrar todos os passos do processo de produção de farinha de mandioca. A farinha é muito boa, pois serve para nos alimentar, se nós não plantamos a mandioca, não vamos ter farinha para o sustento da nossa família. Junto com o plantio da mandioca também plantamos outros tipos de legumes, como abóbora, batata doce etc. A plantação nos dá muito trabalho, as dificuldades são muitas, mas se não plantarmos não vamos ter o que comer. Este vídeo irá mostrar um pouco da realidade de como nós fazemos a farinha para o nosso consumo. A aldeia Pintada fica à aproximadamente $30 \mathrm{~km}$ da cidade de Tocantinópolis, onde se encontram 20 famílias. Por ser tão longe, não temos acesso a transporte facilmente e, às vezes, temos que deslocar para a aldeia São José para poder pegar o transporte, e assim poder vir à cidade. A aldeia Pintada não tem energia, posto de saúde e escola; sem todos esses serviços públicos, é necessário irmos para outras aldeias para poder utilizá-los. A comunidade da aldeia sobrevive apenas da roça. Este trabalho está organizado em dez partes, onde será explicado cada parte da produção e o porquê foi escolhido o tema para produção do vídeo. Será explicado cada passo da produção e quais as dificuldades encontradas para poder realizar este vídeo e também porque é importante a produção de farinha para a minha comunidade. (Diário do aluno G)

Podemos observar que toda a estrutura do texto na versão final, após as intervenções do professor, mudou completamente, apresentando agora todos os pontos que devem conter em uma apresentação do diário. Portanto, o aluno foi capaz de reescrever o texto e produzir uma apresentação coerente com aquilo que se exige nas produções acadêmicas. $O$ texto apresenta um padrão de linguagem escrita conforme estabelece a ortografia oficial. No momento da reescrita, o aluno $\mathrm{G}$ teve a oportunidade de refletir e ser crítico na sua própria prática. Tudo isso contribui para que os alunos alcancem sucesso sob o ponto do letramento acadêmico. Para tanto, é primordial um trabalho docente sistematizado junto aos alunos mediando as atividades envolvendo a produção de textos (escritos e orais). No diário do aluno C, podemos encontrar os mesmos erros de ortografia e pontuação encontrados na apresentação do diário do aluno G ilustrada na Imagem 1. Abaixo, ilustramos um trecho do Diário de processo criativo do aluno C:

Imagem 2. Intervenções no Diário do aluno C 
A pintura (fotografia 02) com jenipapo é usado-usada em disputa territorial e guerras em busca de espaço-_. nós-Nós também pinta-pintamos todo o rosto não para sermos identificados. O jenipapo também é como um fruto-: serve para comer e fortificar, mas os indígenas não o comecomem. A pintura com jenipapo vai muito além de ser somente pintado, elaEla significa a busca de algo ou manifestação. A pintura somente-por

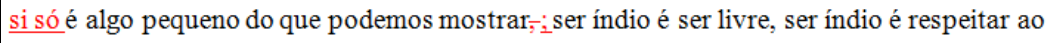
próximo, ser índio com o jenipapo ou sem, é amar e respeita-respeitar a cultura e entender como o outro vive, se é como troupas ou sem roupas, se é com pintura ou não ser índio é viver como índio que sou, e a pintura com jenipapo são-é unisex. A pintura de mulher é somente para mulheres e de homem somente para os homens, e todas as pinturas temtêm

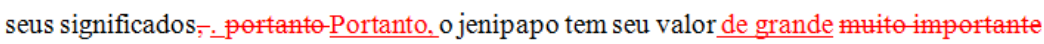
importância e nós apinayés-Apinayé devemos incentivar os mais novos e também sempre nos pintamos, pois não há vergonha nenhuma nisso, amamos a cultura e tudo que tem|nela. [C10] Comentário: Rever. Não está claro. Fonte: Colaborador C, Diário 2 (2016, p. 6).

Nesse trecho do diário do aluno $\mathrm{C}$, aparecem as mesmas inadequações na linguagem apresentadas no diário do aluno G, uma vez que o mesmo escreveu algumas palavras da maneira que elas são pronunciadas na fala popular. Um exemplo é quando diz: “[...] nós também pinta todo o rosto não para sermos identificados", cuja conjugação verbal ocorre da maneira que é falado em situação informal e não segundo o padrão de escrita formal atual da língua portuguesa. É importante destacar que esse problema da conjugação verbal é decorrente da dificuldade que os indígenas colaboradores da pesquisa enfrentam em falar a língua portuguesa, uma vez que os estudantes autores dos diários têm o Apinajé como língua materna, e não o português.

E tais dificuldades foram relatadas pelos discentes Apinajé nas entrevistas, como enfatiza a Aluna I: “[...] é, pra nós índio tem muito dificuldade pra aprender, né? A gente não fala bem o português, mas entende um pouco o português, a gente entende alguma coisa; muito não, mas um pouco". Evidentemente estudar em um idioma que não é sua língua materna exige uma imersão em outra concepção de mundo, uma vez que a lógica de construção de mundo está imbricada na construção da fala, em suas concepções temporais e culturais, o que torna o processo de ensino e aprendizagem ainda mais complexo para um Apinajé. Se levarmos em conta ainda o histórico de opressão e genocídio que esses povos (indígenas) sofreram ao longo dos últimos 500 anos nas Américas, aprender e comunicar-se apenas na língua do colonizador europeu é também um posicionamento político. Portanto, precisamos entender que o português é uma língua adicional para os indígenas assim como o é o inglês para nós brasileiros. Percebe-se a partir da fala da Aluna 
I que na universidade a língua portuguesa acaba sendo uma barreira para os indígenas nas práticas de letramento acadêmico.

No que diz respeito à apresentação linguística do texto ilustrado na Imagem 2, as intervenções do professor focalizam basicamente ortografia, pontuação, concordância e reestruturação de período, um pouco diferente das intervenções presentes no texto da Imagem 1. Todas estas inadequações presentes no texto da Imagem 2 podem ser resolvidas por meio da reescrita, como veremos abaixo na versão final:

A pintura (fotografia 02) com jenipapo é usada em disputa territorial e guerras em busca de espaço. Nós também pintamos todo o rosto não para sermos identificados. O jenipapo também é como um fruto: serve para comer e fortificar, mas os indígenas não o comem. A pintura com jenipapo vai muito além de ser somente pintado. Ela significa a busca de algo ou manifestação. A pintura por si só é algo pequeno do que podemos mostrar; ser índio é ser livre, ser índio é respeitar ao próximo, ser índio com o jenipapo ou sem, é amar e respeitar a cultura e entender como o outro vive, se é com roupas ou sem roupas, se é com pintura ou não ser índio é viver como índio que sou, e a pintura com jenipapo é unisex. A pintura de mulher é somente para mulheres e de homem somente para os homens, e todas as pinturas têm seus significados. Portanto, o jenipapo tem seu valor de grande importância e nós Apinajé devemos incentivar os mais novos e também sempre nos pintamos, pois não há vergonha nenhuma nisso, amamos a cultura e tudo que tem nela. (Diário do aluno C)

Podemos perceber que a prática de reescrita tendo um professor que mantém a relação direta com o aluno e o orienta de maneira eficiente colabora de uma forma expressiva para a escrita reflexiva. Este professor que orienta estes alunos indígenas pelo seu modo no agir docente tornase um agente do letramento, pois de acordo com Kleiman (2007, p. 21)

A formação de um professor para atuar como agente de letramento faz novas e diferentes exigências ao formador universitário: os saberes acadêmicos e a familiaridade com diversas práticas de letramento, inclusive as acadêmicas, são ainda importantes, mas essencial é a atitude de um professor, que, sabendo-se em contínuo processo de letramento, aventura-se a experimentar e, com isso, a continuar aprendendo com seus alunos, através de práticas letradas que motivam o grupo todo e atendem, ao mesmo tempo, a interesses e objetivos individuais e, assim, formam leitores, despertam curiosidades, dão segurança a escritores iniciantes. Para o professor agir assim um dia, em sua prática, precisamos hoje, em seu processo de formação, proporcionar modelos desse fazer.

Entendemos que o professor orientador das produções dos indígenas colaboradores da pesquisa é um agente de letramento nos termos de Kleiman (2007), já que o mesmo busca ler os trabalhos produzidos pelos seus alunos, fazendo com que os discentes em processo de formação compreendam quais as correções/modificações devem realizar nos seus textos, ajustando assim o 
texto ao gênero que este faz parte. Nessa perspectiva, o docente cumpre o papel de agente de letramento na academia/universidade, fazendo com que os alunos em fase inicial de formação prosperem suas práticas de letramento. Podemos ver estas afirmações se concretizando quando o professor, nas suas intervenções, deixa o seguinte bilhete no Diário de processo criativo do aluno:

Imagem 3. Orientações para o aluno C

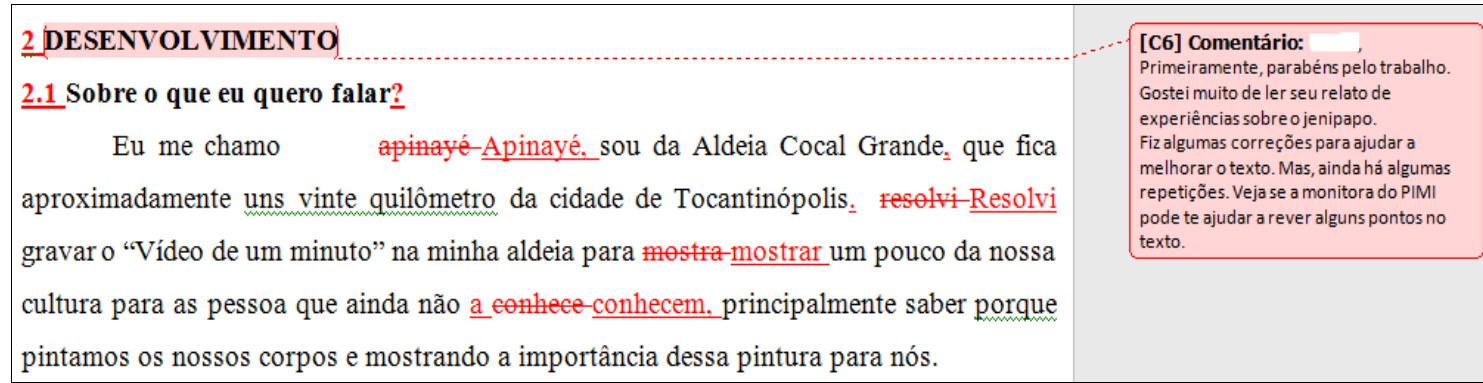

Fonte: Colaborador C, Diário 2 (2016, p. 5).

Além de orientar o seu aluno a respeito das questões ortográficas, pontuação etc., o professor parabeniza-o pelo que o mesmo já realizou (em termos de produção escrita do diário) e não o descrimina pelos erros que aparecem no texto. Além disso, o docente ainda sugere que o discente procure as monitoras do PIMI $^{5}$ para ajudá-lo. Este método de intervenção docente é denominado por Ruiz (2010) como correção textual-interativa. Neste tipo de correção, o professor utiliza-se da proposta do bilhete textual, estabelecendo-se um diálogo entre aluno e professor, evidenciando problemas/inadequações do conteúdo do texto e não somente a sua estrutura; estes bilhetes podem aparecer no corpo, margens ou após o texto, e servem também para incentivar o aluno a reconhecer pontos positivos da produção, como o professor fez no texto do aluno $\mathrm{C}$, assim como para cobrar, deixando deste modo os modelos tradicionais de correções, que no geral se resumem em identificar apenas erros ortográficos, dar um visto e uma nota na produção do aluno.

O professor que acompanha o aluno $\mathrm{C}$, em seu bilhete, cita as monitoras do PIMI, as quais podem auxiliar o discente em suas dificuldades. Não diferente, os dois alunos indígenas

\footnotetext{
${ }^{5}$ O Programa Institucional de Monitoria Indígena (PIMI) é um programa disponibilizado pela UFT com o objetivo de facilitar a inclusão dos alunos indígenas durante as atividades de ensino, pesquisa e extensão, contribuindo assim com a permanência e sucesso destes na universidade. No ano da pesquisa (2018), o programa contava com quatro monitoras bolsistas/remuneradas.
} 
colaboradores da pesquisa também citam as monitoras em seus diários como auxiliadoras nos momentos que estes necessitavam de auxílio, como corroboram os seguintes excertos:

No dia 20 de outubro de 2016, logo após eu ter terminado de fazer todas as gravações, fui até a aldeia São José onde as monitoras do PIMI estavam nos esperando para nos ajudar a fazer nosso trabalho de produção do vídeo e fazer o Diário de processo criativo. Eu mostrei os meus vídeos e minhas anotações para a monitora Milena. Ela viu e disse para eu fazer outras gravações que estavam faltando para eu concluir o meu vídeo. (Diário do aluno G)

A maior dificuldade que tive na hora de gravar esse vídeo foi no momento de conhecer o fruto no pé, pois é muito alto e tinha que subir e a imagem do meu amigo subindo ficava longe. Mas as imagens ficaram muito boas. Outra dificuldade que também encontrei foi na hora de editar, pois não sei muito mexer com o computador. Porém, tive orientação das monitoras do PIMI (Programa Institucional de Monitoria Indígena) que nos orientou como devíamos fazer todo o vídeo. (Diário do aluno C)

Considerando que o programa PIMI tem o objetivo de auxiliar e acompanhar os acadêmicos indígenas nas suas atividades de ensino, pesquisa e extensão, logo, todos os trabalhos que esses alunos desenvolvem na Universidade e necessitam de auxílio as monitoras os auxilia. Como o curso de Licenciatura em Educação do Campo focalizado funciona em regime de alternância pedagógica, quando há necessidade, as monitoras (juntamente com um professor orientador do PIMI) se deslocam até as aldeias durante o TC, e isso fica evidente no trecho do diário do aluno C quando este diz que “[...] tive orientação das monitoras do PIMI (Programa Institucional de Monitoria Indígena) que nos orientou como devíamos fazer todo o vídeo" (Diário do aluno C).

Esses encontros nas aldeias têm a finalidade de compreender as dificuldades apresentadas pelos acadêmicos indígenas, sempre procurando ajudá-los a solucionar, ouvindo sempre e mantendo um diálogo ético, apreciando os conhecimentos indígenas e conhecimentos acadêmicos, proporcionando assim oportunidades e facilidades aos indígenas para sua inclusão na sociedade acadêmica e permanência na universidade. Por estas razões é que os alunos indígenas reconhecem que o PIMI os ajuda no letramento acadêmico com a questão da escrita.

\section{Considerações finais}

A Licenciatura em Educação do Campo foco da pesquisa, instituída com base nos princípios freireanos, apresenta uma abordagem de educação libertadora partindo do meio em que os educandos vivem (FREIRE, 2002), possibilitando assim estabelecer um elo entre o acadêmico e o social. A disciplina de Seminário Integrador é a ferramenta perfeita para que este elo se concretize, 
já que a finalidade dela é a integração semestral no curso, deixando de lado o paradigma encontrado nas licenciaturas tradicionais. As atividades nesta disciplina contemplam (de maneira expressiva) também meios que consideram as práticas escritas da esfera acadêmica, como os gêneros acadêmicos os quais favorecem e promovem o letramento dos estudantes.

Os textos do gênero discursivo Diário de processo criativo analisados neste estudo corroboram que na alternância e nos Tempo Universidade e Tempo Comunidade o conhecimento científico não é analisado de forma que não leve em consideração os meios sociais que os sujeitos fazem parte, mas integrado à realidade do meio social em que o discente e suas famílias vivem, como ilustramos no decorrer das análises dos dados desta pesquisa acerca dos indígenas e o espaço social aldeia. Este gênero propôs aos discentes uma maior integração com a sua cultura e com seu povo, além de mostrar que a Licenciatura em Educação do Campo alicerça suas práticas formativas nos princípios da Pedagogia da Alternância (SILVA, 2011; 2019), de modo a promover o letramento dos discentes.

Os diários de processo criativo, em suas diferentes versões, revelam que os estudantes indígenas Apinajé possuem muitas dificuldades relacionadas à escrita. Vale destacar que as inadequações não ocorrem somente na escrita (ortografia, pontuação, concordância, regência, coesão, coerência, etc.), mas também na estruturação do gênero, reforçando os obstáculos enfrentados pelos indígenas: dificuldade com a língua portuguesa e o uso do computador para editar os textos. Diante disso, o papel do professor se torna indispensável para ajudar os estudantes a superar tais obstáculos, dado que é obrigação do professor, a princípio, orientar/auxiliar o seu aluno em todo o processo de construção de seu trabalho, sanando dúvidas em relação ao uso da língua, estruturação, estilo da linguagem, finalidade do texto etc., sendo o responsável pela potencialização e direção da formação do aluno.

Levando em consideração estes aspectos, podemos destacar que o professor que orientou os dois diários utilizados nas análises ilustradas neste artigo é um agente do letramento (KLEIMAN, 2007), já que o mesmo mantém uma relação direta com o aluno por meio de suas contribuições/intervenções, assim colaborando de forma efetiva para o desenvolvimento da (re)escrita, deixando ao longo dos diários comentários explicitando de maneira clara o que necessita ser alterado/reformulado nos textos e, em outros momentos, deixa apenas perguntas fazendo assim com que o aluno reflita sobre sua própria escrita. 
Tendo em vista os aspectos observados, podemos afirmar que o Diário de processo criativo é um gênero discursivo de grande importância para a formação dos estudantes, já que, além de trazer o registro das atividades vinculadas a um tema gerador e produção de um audiovisual, possibilitou ao aluno relatar sua experiência ao longo desta atividade e mostrar suas experiências científicas e sociais no cotidiano, lembrando que estes são dois espaços de formação, os quais apresentam práticas e eventos de letramentos diversos que são essenciais para a formação destes indivíduos. Sem dúvidas, a produção desse diário favoreceu a ampliação do letramento acadêmico dos alunos indígenas colaboradores da pesquisa. Contudo, é importante ressaltar que esses atores sociais enfrentam muitos obstáculos na universidade.

Assim, gostaríamos de destacar que, apesar de todas as agruras do caminho em busca de formação na universidade, os Apinajé colaboradores da pesquisa lutam para ingressar na Licenciatura em Educação do Campo da UFT e conseguir integralizá-la, como revela a Aluna I:

E eu tô fazendo esse curso de Educação do Campo é porque esse é meu sonho de ser professora, ajudar o meu povo, que é muito importante. Eu preciso ajudar o meu povo, que eu sempre sonho de ser professora da aldeia, preciso ajudar o meu povo também que precisa de nós também indígena como professora, né? [...] às vezes o nosso povo não sabe falar ainda o português, a gente precisa ajudar se um dia a gente chegar ser professora eu quero ajudar os que tão precisando que a gente fala o português e na língua [Apinajé] também. (Entrevistada com a Aluna I)

A partir dessa fala da estudante, chamamos a atenção para o fato de que o simples acesso à universidade não pode ser traduzido como um processo de inclusão. Compreendemos que "a inclusão acontece, de fato, quando a identidade do aluno indígena é preservada, mantida e respeitada. A atual organização da universidade, em suas diversas dimensões, acaba por sintetizar uma escuta que se fecha para a realidade do aluno indígena" (BRASIL; SILVA, 2020, p. 7). No caso específico da UFT, ela já avançou bastante em termos de inclusão, mas é preciso propiciar condições ainda melhores para que os indígenas que ingressam em seus cursos tenham condições de concluí-los. A universidade não pode apenas ver os indígenas ingressando em seus cursos e não promover ações efetivas no intuito a ajudá-los a integralizar seu curso. E uma das ações importantes que podem e devem ser desenvolvidas é a promoção, a partir das reais dificuldades dos discentes indígenas com a leitura e produção de gêneros acadêmicos, de projetos para dar subsídios a eles na universidade, de modo que possam melhorar as capacidades de leitura e escrita. Evidentemente, o 
trabalho desenvolvido pelo professor que orientou os estudantes indígenas na elaboração dos Diários de processo criativo vai nessa direção.

\section{Referências}

ALMEIDA, Rejane Cleide Medeiros de. "Movimentos sociais do campo e práxis política: trajetória de luta por uma educação do campo no Tocantins". SILVA, Cícero da; MIRANDA, Cássia Ferreira; AIRES, Helena Quirino Porto; OLIVEIRA, Ubiratan Francisco de (Orgs.). Educação do Campo, artes e formação docente. Palmas: EDUFT, 2016. p. 25-52.

ARAÚJO, Camila Maria de; BEZERRA, Benedito Gomes. Letramentos Acadêmicos: leitura e escrita de gêneros acadêmicos no primeiro ano do curso de letras. DIÁLOGOS - Revista de Estudos Culturais e da Contemporaneidade, Garanhuns, v. 1, n. 9, p. 5-37, 2013.

BAKHTIN, Mikhail. Os gêneros do discurso. In: BAKHTIN, Mikhail. Estética da criação verbal. 4. ed. São Paulo: Martins Fontes, 2006. p. 261-335.

BRASIL, Anderson; SILVA, Cícero da. O povo indígena Apinayé e o acesso à Licenciatura em Educação do Campo da Universidade Federal do Tocantins: algumas reflexões. Arquivos Analíticos de Políticas Educativas, Tempe, v. 28, p. 1-14, 2020. (no prelo).

BRASIL. Decreto $n^{\circ} 7.352$, de 4 de novembro de 2010. Dispõe sobre a política de educação do campo e o Programa Nacional de Educação na Reforma Agrária - PRONERA. Brasília. Disponível em: http://www.planalto.gov.br/ccivil_03/_ato2007-2010/2010/decreto/d7352.htm Acesso em: 15 jun. 2020.

BRASIL. Edital de Seleção no 02/2012 - SESU/SETEC/SECADI/MEC de 31 de agosto de 2012. Brasília. Disponível em:

http://portal.mec.gov.br/index.php?option=com_docman\&task=doc_download\&gid=13300\&Ite $\underline{\text { mid }}=$ Acesso em: 15 jun. 2020.

BRITO, Áustria Rodrigues; LIMA, Lindalva da Silva. Letramentos e ensino no contexto da educação básica. Entreletras, Araguaína, v. 9, n. 2, p. 410-429, jul./set. 2018.

EUZÉBIO, Michelle Donizeth; CERUTTI-RIZZATTI, Mary Elizabeth. Usos sociais da escrita: um estudo sobre práticas e eventos de letramento na vivência de professoras alfabetizadoras. Ling. (dis)curso, Tubarão, v. 13, n. 1, p. 13-34, 2013. doi: https://doi.org/10.1590/S1518$\underline{76322013000100002}$

FISCHER, Adriana. Letramento acadêmico: uma perspectiva portuguesa. Acta Scientiarum. Language and Culture, Maringá, v. 30, n. 2, p. 177-187, 2008.

FONSECA, Regina Célia Veiga da. Metodologia do Trabalho Científico. Curitiba: IESDE Brasil, 2012.

FREIRE, Paulo. Pedagogia da Autonomia: saberes necessários à prática educativa. Editora Paz e Terra, 2002.

KLEIMAN, Angela B. Os significados do letramento: uma nova perspectiva sobre a prática social da escrita. Campinas: Mercado de Letras, 1995. 
KLEIMAN, Angela B. Letramento e suas implicações para o ensino de Língua Materna. Signo, Santa Cruz do Sul, v. 32, n 53, p. 1-25, dez, 2007.

KLEIMAN, Angela B. Projetos dentro de projetos: ensino-aprendizagem da escrita na formação de professores de nível universitário e de outros agentes de letramento. Scripta, Belo Horizonte, v. 13, n. 24, 17-30, 2009.

LÊDO, Amanda Cavalcante de Oliveira. Letramentos acadêmicos: práticas e eventos de letramento na educação a distância. 2013. 153f. Dissertação (Mestrado em Letras) Universidade Federal de Pernambuco, Recife, 2013.

MARINHO, Marildes. A escrita nas práticas de letramento acadêmico. Revista Brasileira de Linguística Aplicada, Belo Horizonte, v. 10, n. 2, p. 363-386, 2010. doi: https://doi.org/10.1590/S1984-63982010000200005

MENEGASSI, Renilson José. Professor e escrita: a construção de comandos de produção de textos. Trabalhos em Linguística Aplicada, Campinas, v. 42, p. 55-79, 2003.

MOLINA, Mônica Castagna. Expansão das licenciaturas em Educação do Campo: desafios e potencialidades. Educar em Revista, Curitiba, n. 55, p.145-166, jan./mar., 2015. doi: https://doi.org/10.1590/0104-4060.39849

NASCIMENTO, André Marques do. Apontamentos críticos sobre concepções de linguagem na formação superior de docentes indígenas: diálogo intercultural como diálogo interepistêmico. Muitas Vozes, Ponta Grossa, v. 3, n. 1, 103-123, 2014.

NIMUENDAJÚ, Curt. Os Apinayé. Boletim do Museu Paraense Emílio Goeldi, Belém, n. 12, p. 1-150, 1956. Disponível em: https://repositorio.museu-goeldi.br/handle/mgoeldi/865 Acesso em: 10 abr. 2020.

OLIVEIRA, Eliane Feitoza. Letramento acadêmico: Principais abordagens sobre a escrita dos alunos do ensino superior. Anais... II Encontro Memorial do Instituto de Ciências Humanas e Sociais. Mariana, 2010. Disponível em: www.ichs.ufop.br/memorial/trab2/1113.pdf. Acesso em: 03 abr. 2018.

PAULA, Leon de; BONILLA, Marcus Facchin; SILVA, Cícero da. Campo em vídeo: experiências artístico-educativas na produção de audiovisuais no norte do Tocantins. In: SILVA, Cícero da; MIRANDA, Cássia Ferreira; AIRES, Helena Quirino Porto; OLIVEIRA, Ubiratan Francisco de (Orgs.). Educação do Campo, artes e formação docente. Palmas: EDUFT, 2016. p. 169-194.

PEREIRA, Rodrigo Acosta; RODRIGUES, Rosângela Hammes. Perspectivas atuais sobre gêneros do discurso no campo da linguística. Revista Eletrônica de Divulgação Científica em Língua Portuguesa, Linguística e Literatura, Ano 05, n. 11, p. 1-18, 2009.

ROJO, Roxane Helena Rodrigues. Letramentos múltiplos, escola e inclusão social. São Paulo: Parábola Editorial, 2009.

RUIZ, Eliana Donaio. Como corrigir redações na escola. São Paulo: Contexto, 2010.

SANTOS, Maria de Fátima Ribeiro dos; SANTOS, Ribeiro dos. Metodologia da pesquisa em educação. São Luís: Uemanet, 2010. 
SANTOS, Milena dos. Letramento acadêmico: reflexões sobre a produção de gêneros acadêmicos por estudantes indígenas em uma licenciatura em Educação do Campo. 2018. 84f. Monografia (Curso de Licenciatura em Educação do Campo: Artes e Música) - Universidade Federal do Tocantins, Tocantinópolis, 2018.

SANCHEZ, Sandra. Instrumentos da Pesquisa em Educação. 2012. Disponível em: http://www.ia.ufrrj.br/ppgea/conteudo/conteudo20121/1SF/Sandra/Instrumentos\%20e\%20T\%C3 \%A9cniccas\%20de\%20pesquisa.ppt. Acesso em: 04 mai. 2018.

SILVA, Cícero da. Pedagogia da Alternância: um estudo do gênero Caderno da Realidade com foco na retextualização. 2011. 149f. Dissertação (Mestrado em Letras: Ensino de Língua e Literatura) - Universidade Federal do Tocantins, Araguaína, 2011.

SILVA, Cícero da. Formação e letramento no contexto de ensino da Pedagogia da Alternância: alguns apontamentos. Entrepalavras, Fortaleza, v. 9, n. 2, p. 473-491, 2019. doi: http://dx.doi.org/10.22168/2237-6321-21667

SILVA, Cícero da et al. Licenciatura em Educação do Campo com Habilitação em Artes e Música: trajetória e desafios na Região do Bico do Papagaio, Brasil. Revista Triângulo, Uberaba, v. 10, n. 1, p. 73-95, 2017. doi: https://doi.org/10.18554/rt.v10i1.2186

SILVA, Edna Cristina Muniz da. Gênero e práticas de letramento no ensino fundamental. 2007. 266f. Tese (Doutorado em Linguística: Linguagem e Sociedade) - Universidade de Brasília, Brasília, 2007.

SILVA, Elizabeth Maria da; ARAÚJO, Denise Lino de. Letramento: um fenômeno plural. Revista Brasileira de Linguística Aplicada, Belo Horizonte, n. 12, n. 4, p. 681-698, 2012. doi: https://doi.org/10.1590/S1984-63982012005000007

SILVA, Jane Quintiliano G. Gênero discursivo e tipo textual. SCRIPTA, Belo Horizonte, v. 2, n. 4, p. 87-106, 1999.

SOARES, Magda. Letramento: um tema em três gêneros. 3. ed. Belo Horizonte: Autêntica, 2019.

STREET, Brian V. Letramentos sociais: abordagens críticas do letramento no desenvolvimento, na etnografia e na educação. Tradução Marcos Bagno. São Paulo: Parábola Editorial, 2014.

LEA, Mary R.; STREET, Brian V. O modelo de 'letramentos acadêmicos': teoria e aplicações. Filol. Linguíst. Port., São Paulo, v. 16, n. 2, p. 477-493, 2014.

TINOCO, Glícia M. Azevedo de M. Projetos de letramento: ação e formação de professores de língua materna. 2008. 254f. Tese (Doutorado em Linguística Aplicada) - Instituto de Estudos da Linguagem, Universidade Estadual de Campinas, Campinas, 2008.

UFT. Projeto Político Pedagógico do Curso de Licenciatura em Educação do Campo: Linguagens e Códigos Artes e Música. Tocantinópolis: s/n, 2016.

Recebido em 14 de julho de 2020 Aceito em 31de agosto de 2020 